\title{
Effects of pre-cracks on both initiation and propagation of re-bar corrosion in pure carbon dioxide
}

\author{
Vu Hiep Dang ${ }^{1}$, Raoul François ${ }^{1}$, Valérie L’Hostis ${ }^{2}$ \\ ${ }^{1}$ Université de Toulouse ; UPS, INSA ; LMDC ; Toulouse, France \\ ${ }^{2}$ CEA Saclay, CEA, DEN, DPC, SECR, Laboratoire d'Etude du Comportement des Bétons et des \\ Argiles, F-91191 Gif-sur-Yvette, France
}

\begin{abstract}
This paper deals with effects of pre-cracks on both initiation and propagation of reinforcement steel corrosion due to carbonation. The ring shaped mortar samples with $8 \mathrm{~mm}$ steel bar inside were cracked with different crack widths ranging from 12 micrometers to 600 micrometers and then subjected to carbon dioxide environment for different terms to assess the carbonation profile in cracks and along the interface between steel and concrete, damaged by the internal pressure applied to the ring samples. After carbonation of interface, ring samples were submitted to wetting-drying cycles to study the propagation of corrosion and the effect of corrosion products on healing and then repassivation of steel bar or corrosion cracks development. Results show that irrespective of width of cracks, the carbon dioxide reaches the interface between steel and mortar and propagates along this interface. The samples then subjected to wetting-drying cycles exhibit corrosion development all along the interface, the appearance of oxides does not lead to create corrosion cracks for the duration of the experiments.
\end{abstract}

\section{Introduction}

Corrosion evaluation of reinforcing steel embedded in the concrete structures is a very serious problem and it is difficult to determine the corrosion rate because the steel is not visible. The primary cause for the corrosion of reinforced bar is due to the presence of chloride ions and the diffusion of carbon dioxide gas from the atmosphere. Chloride ions locally ruin the passive film provoking localized or pitting corrosion. On the other hand, carbon dioxide reduces the $\mathrm{pH}$ of the pore solution, making the passive film destroyed and causing generalized corrosion. The corrosion by carbon dioxide is less studied than by chlorides but may be also dangerous because of failure in the reduced cross section of reinforcement since the mechanical capacity of these sections may be lower than necessary for serviceability and ultimate service life.

There are numerous causes of cracking in concrete such as: shrinkage, settlement, freeze/thaw cycles, creep, design loads, formwork movement, corrosion of reinforcement and so on [1]. The existence of pre-cracks could accelerate the corrosion process by a quicker depassivation of the steelconcrete interface since the cracks create pathways for oxygen, chlorides, carbon dioxide, and water into concrete. There were numerous studies on the chloride diffusion in a crack of concrete members 
[3-7]. According to them, for long term corrosion the presence of cracks and crack widths has the influence on corrosion propagation [7] but others believe that the crack width has no impact on the development of reinforcement corrosion $[3,5,6]$. One point, which seems critical in the development of the corrosion process in relation to pre-cracks, is the possibility to obtain healing of crack with corrosion products or to obtain the creation of corrosion cracks due to corrosion process at the intersection of crack with the re-bars.

Contrary to chloride environment, the effect of crack openings on the diffusion of carbon dioxide to the steel-concrete interface has not been widely studied. However, S. Alahmad et al. [2] investigated the influence of crack opening on carbon dioxide penetration in cracked ring-shaped mortar samples. They found that crack opening significantly affects the ability of carbon dioxide to diffuse along the crack walls. Moreover, the carbonation of the interface between steel and mortar always exists regardless of pre-crack widths. The creation of the corrosion cracks and the effect of rust on healing when the samples corrode in carbon dioxide then subject to cyclic wetting-drying, however, have not been studied. The corrosion process at steel-concrete interface of cracked members is whether controlled by the diffusion rate of $\mathrm{CO}_{2}$ through crack walls.

The aim of this paper is to observe how the carbonation progresses through cracks to reach the steel bar at the interface of mortar-steel bar happens and if crack width is correlated with the damage at interfacial steel-mortar.

\section{Experimental methods}

\subsection{Materials}

All the mortar samples were fabricated with a French CPA cement (CEMI 52.5R) having $\mathrm{C}_{3} \mathrm{~S}, \mathrm{C}_{2} \mathrm{~S}$, $\mathrm{C}_{3} \mathrm{~A}$ and $\mathrm{C}_{4} \mathrm{AF}$ contents of $67.8 \%, 7.1 \%, 8.6 \%$, and $6.2 \%$, respectively. The standard sand (CEN EN 196-1) was used. All the mortar mixtures were made with a water/cement ratio of 0.48 and a sand/cement ratio of 2.72. Each mortar mixture was made with $1.380 \mathrm{~kg}$ of water, $2.875 \mathrm{~kg}$ of cement, and $7.830 \mathrm{~kg}$ of fine aggregate. Deformed steel bars of $8 \mathrm{~mm}$ diameter were used as reinforcement in the ring shaped mortar samples. The elastic limit of steel used was 500Mpa. The test samples consist of ring shaped mortar of $50 \mathrm{~mm}$ height, $150 \mathrm{~mm}$ external diameter, $50 \mathrm{~mm}$ internal diameter as shown in Fig.1a. For each sample, a deformed steel bar 8mm of circular shape with $100 \mathrm{~mm}$ diameter was kept at center of mould by three fixed metal wires. The mould was filled in two steps with a vibration of 30 seconds on a vibrating table at the end of each step. After $24 \mathrm{~h}$, the samples were carefully unmoulded to avoid any cracking and then cured under tap-water until 28 days.

\subsection{Preconditioning of the samples}

After curing, the all samples were kept in an oven to dry completely at $40^{\circ} \mathrm{C}$ for 50 days. The mass of each sample was weighed at 2 weeks interval by an electric balance with accuracy of $0.001 \mathrm{~kg}$. Then the mass was compared each other in order to confirm the absolute drying of samples. The aim of drying the samples is to accelerate the carbonation process. 


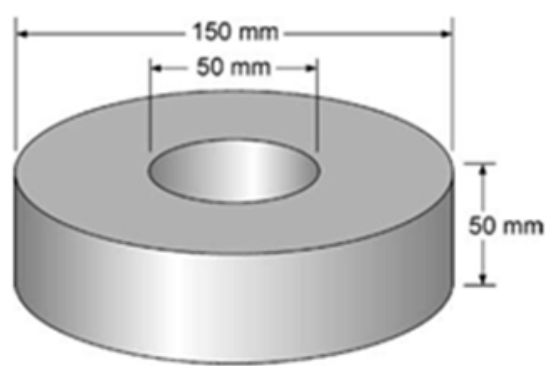

(a)

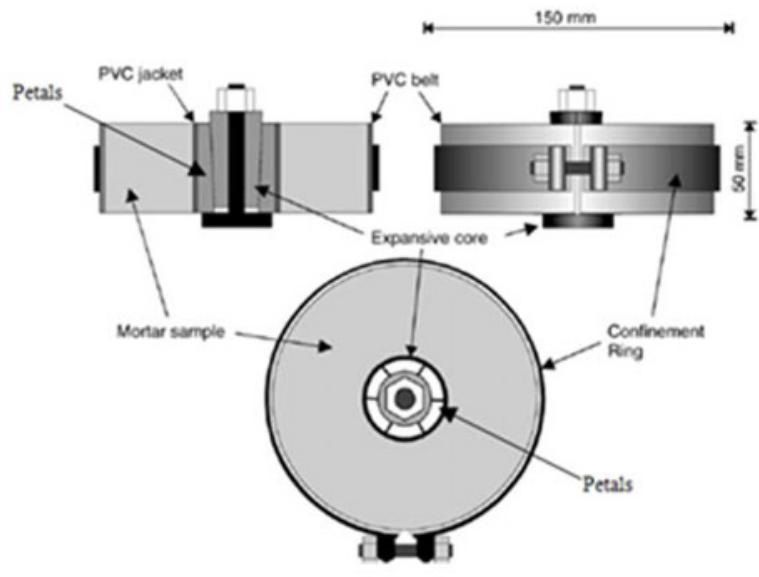

(b)

Fig. 1. a) Dimensions of the ring mortar sample, b) Apparatus for creating cracks on samples.

\subsection{Cracking of the mortar samples}

Controlled cracking of samples was obtained by the experimental procedure used by Gagne et al. [8] and S. Alahmad et al. [2]. Cracks induced by the expansive core are radial. The number and opening depend on the load applied. Prior to making cracks on the samples, both exterior and interior surfaces were polished by carbon silica powder (number 120) to obtain flat smooth surfaces. The samples were subjected to control the tensile cracking with a mechanical expansive core and an external steel confinement ring (Fig.1b). The expansive core which was inserted into the sample hub consisted of a conical hardened-steel cylinder that slide inside a set of six conical hardened-steel petals. A thin cylindrical PVC jacket held the petals around the conical cylinder. A high-strength steel bolt and nut were used to force the conical cylinder against the petals. This process caused the diameter of the PVC jacket to increase, thus inducing deformation in the internal diameter of the mortar sample. Controlled cracking was achieved by manually adjusting the deformation of the expansive core. During the whole process the sample surfaces were closely monitored and crack widths were detected and measured by a portable video microscope in order to reach the desired crack widths. It should be noted that there were not longitudinal cracks arisen along exterior perimeter of samples during this stage.

\subsection{Exposure conditions}

Immediately after the mortar disks had been cracked, they were transferred to a sealed chamber and subjected to carbonation at a temperature of $23^{\circ} \mathrm{C}$, a relative humidity of $65 \%$ and a $\mathrm{CO}_{2}$ concentration of around $50 \%$. For each sample group, the exposure time in $\mathrm{CO}_{2}$ was different that ranges from one week to several months. After keeping in $\mathrm{CO}_{2}$, the corrosion of some sample groups was studied thanks to wet-dry cycles: one day under tap water-six days in lab atmosphere. With series $\mathrm{C}$ samples, the cycles consist of one day wetting under tap water and three days drying in lab air. Table 1 gives the detailed experiment condition for all six groups. At different periods, the samples were chosen to analyze the corrosion pattern. 
Table 1. Groups and exposure environment for accelerating corrosion.

\begin{tabular}{|c|c|c|c|c|}
\hline & \multicolumn{4}{|c|}{ Cracking samples } \\
\hline Name goup & $\mathrm{M}$ & $\mathrm{C}$ & $\mathrm{N}$ & $\mathrm{S}$ \\
\hline Quantity & 5 & 2 & 7 & 7 \\
\hline Exposure in CO2 & Yes & Yes & Yes & Yes \\
\hline $\begin{array}{c}\text { Cyclic wetting- } \\
\text { drying }\end{array}$ & No & Yes & Yes & Yes \\
\hline
\end{tabular}

The ring samples taken out of carbonation chamber were broken into two halves: upper (top) half and lower (bottom) half and then carbonation depths measured. For series $\mathrm{M}$ samples, the purpose is to study the corrosion progress at the interface of steel-mortar and along crack path by destructive test. Therefore, the cyclic wet-dry did not carry out for these series. The duration of the accelerated test for each of groups of cracking samples is specifically indicated in table 2. To C samples, only C2 sample was corroded by made cycles of one day wetting under tap water and 3 days drying in the laboratory environment.

\section{Experimental results and discussion}

\subsection{Crack characteristics}

The table 2 gives the measured crack openings and the number of cracks on two faces of specimens with help of portable video microscope. The crack opening varies from $12 \mu \mathrm{m}$ to $595 \mu \mathrm{m}$. The difference between crack opening of the top face and bottom face is quite larger, which ranges from few dozen to several hundred micrometers, depending on the force against PVC jacket.

The carbonation in cracked concrete samples is a major factor that promotes the corrosion of embedded reinforcing steel. Therefore, in terms of the durability of concrete, it is necessary to control cracks formed during the life of a structure. R. Francois and J.C. Maso [11] investigated the influence of sustained load on carbonation or on chloride penetration of RC beams. The results showed that the damage to the aggregate-cement paste interface increases the penetration of aggressive agents in the tension zone. The carbonation depth was always greater than in the tension zone whatever the load levels and time of exposure. They found that there was the diffusion along steel bars from the intersection between crack path and reinforcement. S. Alahmad et al. [2] who tested the disk samples with the same composition of mortar and dimensions as this study concluded that for crack widths below $9 \mu \mathrm{m}$, the carbonation did not occur on the face perpendicular to the crack wall. Nevertheless, they found that the interface between steel and mortar was carbonated even if this carbonation did not progress perpendicular to the interface, being superficial for the duration of experiment. From above discussions, it could be predicted that all cracked mortar samples in Table 2 will be at least superficially carbonated through crack path.

\subsection{Carbonation and initiation of reinforcement steel corrosion}

It is well known that the depassivation of steel bars embedded in concrete can occur for an alkaline $\mathrm{pH}$ between 9 and 11[12] or ranging from 8.3 to 12.6 [13], and thus be associated with a partial 
carbonation of concrete cover. In order to understand whether carbonation penetration along interface between mortar and steel bar occurs or not, a phenolphthalein $\mathrm{pH}$ indicator was used. Each sample was broken into upper half and lower half along its outer perimeter. The phenolphthalein was then sprayed on the fresh mortar surface. The series $M$ were analyzed after 1 to 5 weeks in carbon dioxide. At that time, carbonation process at mortar rebar interface was initiated for M5 sample, which was just exposed to carbon dioxide chamber within one week (see in Fig.2). It can be observed the white-purplish colored region on the interface between reinforcement and mortar of M5 sample. This implies that the carbonation started to spread over interface. It is also different from results obtained on the same samples but exposed to chloride where the corrosion progressed only few millimeters along interface from crack path [10]. We remark that there was a change in color at interface as the phenolphthalein was sprayed. Immediately after the spraying completed, the color did not alter along the interface. Nevertheless, carbonation appears to be very superficial since after few minutes the color changes due to re-increased of $\mathrm{pH}$ at steel-mortar interface as shown in Fig.3. A possible explanation is that the pore solution which is still basic $(\mathrm{pH}=13)$ goes to fresh surface because of drying of sample exposed to the lab condition.

The M2 specimen subjecting to carbon dioxide for 5 weeks exhibited the almost completed carbonation process along interface since no color change observed on the interface after half an hour. Surprisingly, $\mathrm{CO}_{2}$ which diffuses into crack path to reach the reinforcement leaded to a total carbonation of interface. This result is different from those obtained on flexural members stored in sustained loading in onsite atmosphere where carbonation appears only few centimeters along interface [11]. In other words, carbonation of interface was stable. Fig. 2c presents the carbonation front at crack face after 5 weeks of exposure. Similarly to M5 specimen, with the presence of precrack path the carbonation process occurred partly on the crack face. The depth of carbonation measured on cracked surface was approximately $1.5 \mathrm{~mm}$. Therefore, any carbonation along the steelconcrete interface must be due to carbon dioxide gas through cracks. In fact, if the carbon dioxide gas could penetrate through the electrical wire or along three wires, which maintained the ring steel bar, this will not change the conclusion that interface between steel bars and mortar is fully carbonated since $\mathrm{CO}_{2}$ can reach the re-bars.

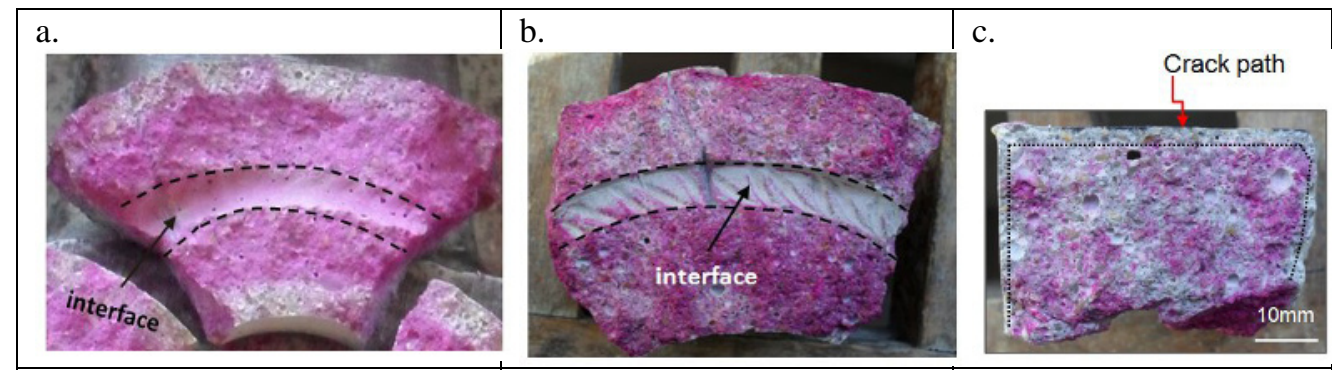

Fig. 2. Evolution of carbonation at steel bar-mortar interface: a) M5 sample ; b) M2 sample, c) Carbonation depth of M2 perpendicular to the crack face. 
Table 2. Crack widths and exposure environment of tested samples.

\begin{tabular}{|c|c|c|c|c|c|c|c|c|c|c|c|}
\hline \multirow{3}{*}{ Name } & & \multicolumn{8}{|c|}{ No. of cracks } & \multirow{3}{*}{$\begin{array}{c}\text { Duration } \\
\text { in } \mathrm{CO} 2\end{array}$} & \multirow{3}{*}{$\begin{array}{c}\text { No. } \\
\text { of } \\
\text { cycles }\end{array}$} \\
\hline & & 1 & 2 & 3 & 4 & 5 & 6 & 7 & 8 & & \\
\hline & & \multicolumn{8}{|c|}{ Crack width- $\mu m$} & & \\
\hline \multirow{2}{*}{ M1 } & Top face & 43 & 72 & 56 & 59 & - & - & - & - & \multirow{2}{*}{ 3ws } & \multirow{2}{*}{ - } \\
\hline & Bottom face & 22 & 32 & - & - & - & - & - & - & & \\
\hline \multirow{2}{*}{ M2 } & Top face & 12 & 13 & - & - & - & - & - & - & \multirow{2}{*}{$5 w s$} & \multirow{2}{*}{-} \\
\hline & Bottom face & 21 & 38 & 43 & 40 & 34 & - & - & - & & \\
\hline \multirow{2}{*}{ M3 } & Top face & 98 & 99 & - & - & - & - & - & - & \multirow{2}{*}{$2 \mathrm{ws}$} & \multirow{2}{*}{ - } \\
\hline & Bottom face & 50 & 17 & 95 & 43 & - & - & - & & & \\
\hline \multirow{2}{*}{ M4 } & Top face & 65 & 67 & 107 & - & - & - & - & - & \multirow{2}{*}{ 4ws } & \multirow{2}{*}{-} \\
\hline & Bottom face & 36 & 29 & 27 & - & - & - & - & - & & \\
\hline \multirow{2}{*}{ M5 } & Top face & 68 & 75 & 60 & & - & - & - & - & \multirow{2}{*}{ 1ws } & \multirow{2}{*}{-} \\
\hline & Bottom face & 20 & 33 & 55 & 72 & - & - & - & - & & \\
\hline \multirow{2}{*}{$C 1$} & Top face & 138 & 34 & 140 & 595 & 141 & 203 & - & - & \multirow{2}{*}{$13 w s$} & \multirow{2}{*}{-} \\
\hline & Bottom face & 105 & 153 & 171 & 99 & 289 & 311 & - & - & & \\
\hline \multirow{2}{*}{$C 2$} & Top face & 230 & 52 & 64 & - & - & - & - & - & \multirow{2}{*}{ 23ws } & \multirow{2}{*}{6} \\
\hline & Bottom face & 395 & 180 & 161 & 93 & 140 & 394 & - & - & & \\
\hline \multirow{2}{*}{ S3 } & Top face & 125 & 98 & 86 & 111 & - & - & - & - & \multirow{2}{*}{ 7ws } & \multirow{2}{*}{-} \\
\hline & Bottom face & 33 & 22 & 15 & 38 & - & - & - & - & & \\
\hline \multirow{2}{*}{ S6 } & Top face & 81 & 57 & 70 & - & - & - & - & - & \multirow{2}{*}{$15 \mathrm{ws}$} & 14 \\
\hline & Bottom face & 33 & 30 & 141 & 166 & 91 & 50 & 62 & - & & \\
\hline$N 1$ & Top face & 300 & 421 & 404 & 366 & 178 & - & - & - & 21 & קO \\
\hline & Bottom face & 129 & 83 & 235 & 145 & 233 & 256 & 215 & 73 & & \\
\hline & Top face & 157 & 274 & 210 & 167 & 259 & 217 & - & - & & \\
\hline & Bottom face & 240 & 140 & 164 & 132 & 145 & - & - & - & & 1. \\
\hline
\end{tabular}




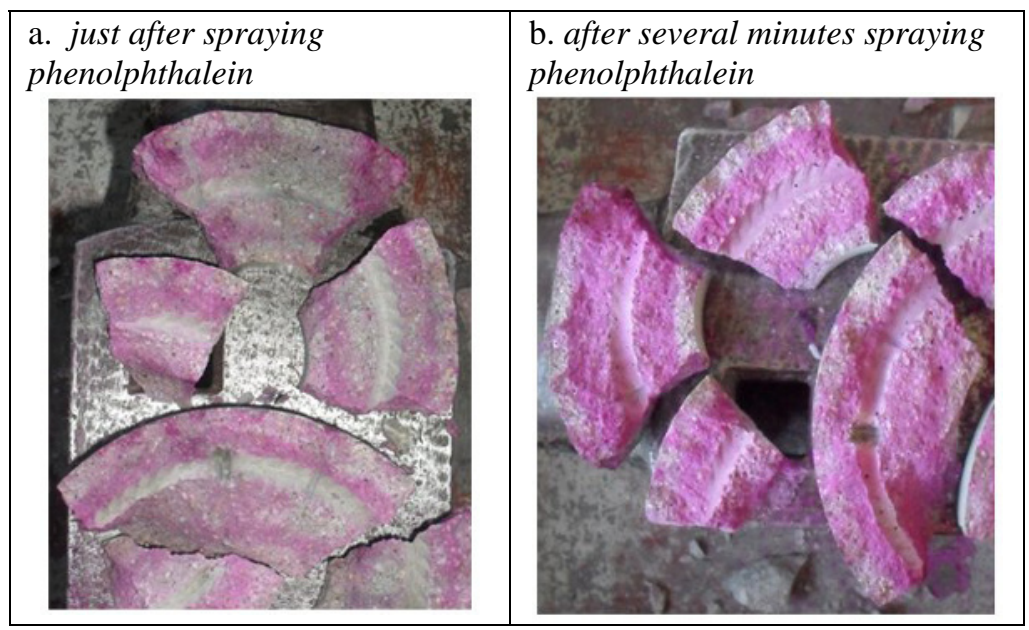

Fig. 3. Change in $\mathrm{pH}$ at interface of reinforcement-mortar (M5) as spraying phenolphthalein.

\subsection{Development of reinforcement steel corrosion}

The diffusion of carbon dioxide into the interior of a concrete structure depends mainly on two parameters: the existence of cracks and the porosity of concrete. The carbonation process through a crack consists of four steps: diffusion of carbon dioxide into the crack, diffusion of carbon dioxide into the concrete, occurrence of chemical reaction and consumption of hydroxyl ions $\mathrm{OH}^{-}$.The initiation of steel bar corrosion in the presence of crack is evidently much faster than it in the absence of crack. The experimental results present that for S3 sample after exposure time of seven weeks to $\mathrm{CO}_{2}$, the interface and crack face were carbonated and the carbonation front provided by the phenolphthalein test was approximately $10 \mathrm{~mm}$. On the steel-concrete interface, some traces of corrosion product were visible. The brown-rust was also more observed on the interface of S6 sample (fig.4b). More rust product also attached to the interface of N1 sample (fig.4d). The samples C2 and N2 with mechanical average crack width of $173 \mu \mathrm{m}$ and $191 \mu \mathrm{m}$ respectively indicated a generalized corrosion along the ring steels. Unlike corrosion pattern caused by chloride ingress, the corrosion pattern of these samples spread over the steel-concrete interface even when the period of time for accelerating corrosion was short term. The appearance of voids between reinforcement and mortar due to "top-cast bar" effect and creation of mechanical cracks which damaged the interface zone could the possible reasons to allow the spreading of carbon dioxide gas along it. For N1 and N2 samples, no corrosion cracks were detected on outer face after 410 days and 240 days respectively of exposure under accelerated conditions. Probably, the pressure results from the formation of oxides and tensile stresses generated by creating of mechanical cracks are still not enough to exceed the tensile strength of the mortar. It should be noted that both of them have the same exposure time to $\mathrm{CO}_{2}$ but the number of cycles of wetting and drying of $\mathrm{N} 1$ is more important than that of N2 sample. This major reason explains why the corrosion state of N1 sample is more severe than the corrosion state of N2 sample at steel-mortar interface. We examine further the corrosion propagation of ring reinforcement steel in C2 sample as shown in Fig.5. The mechanical cracks are located on each face of the steel bar. It can be seen that the view from top face of the ring bar exhibited fewer cracks than the view from its bottom face and the distribution of cracks is irregular. On the top face, the portion 
without cracks revealed no corrosion remaining on this face of the steel bar. On the contrary, the bottom face showed a general corrosion on entire perimeter.

Primarily observing the distribution of corrosion around the steel face, it can see that the corrosion product is irregularly distributed on both bottom face and top face of ring steel. Indeed, as demonstrated in Fig. 6, the thickness of corrosion layer measured by the optical microscopy technique on C2 sample is very different for a given cross section, varying from $0 \mu \mathrm{m}$ to $86 \mu \mathrm{m}$ around the same sample. This implies that there are differences in the carbonation rate along reinforcement steel. The test results also revealed that when the rust layer increases, some cracks parallel to the metal-corrosion product interface appear. As a result, the corrosion protection ability of this layer is poor.

Figures 6 and 7 offer the pictures about metallographic cross sections of C2 and S6 samples that show the rust layer is composed of laminar layers of different colors. The inner part of the rust layer, which is in contact with the steel, is very thin with lighter color. Whereas, the outer part of oxide layer with grey-dark brown in color, close to the cement paste, has the larger thickness. Interestingly, the C2 sample was fully carbonated but partly corroded meanwhile S6 sample was fully corroded but partly carbonated. In this case, the presence of mechanical cracks and time of exposure seem more important than the width of pre-cracks.

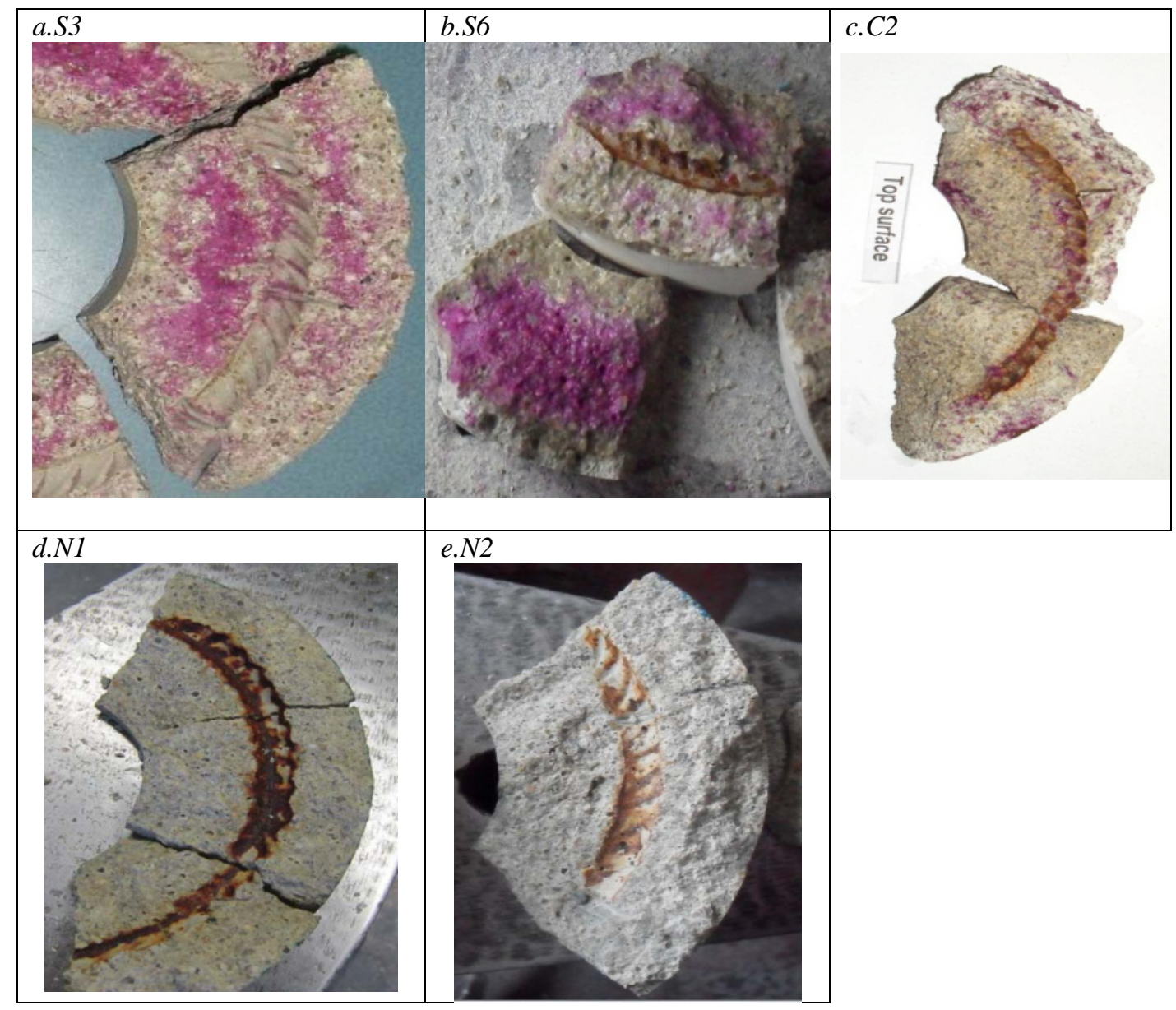

Fig. 4. Evolution of corrosion of S3, S6, C2, N1, N2 samples. 


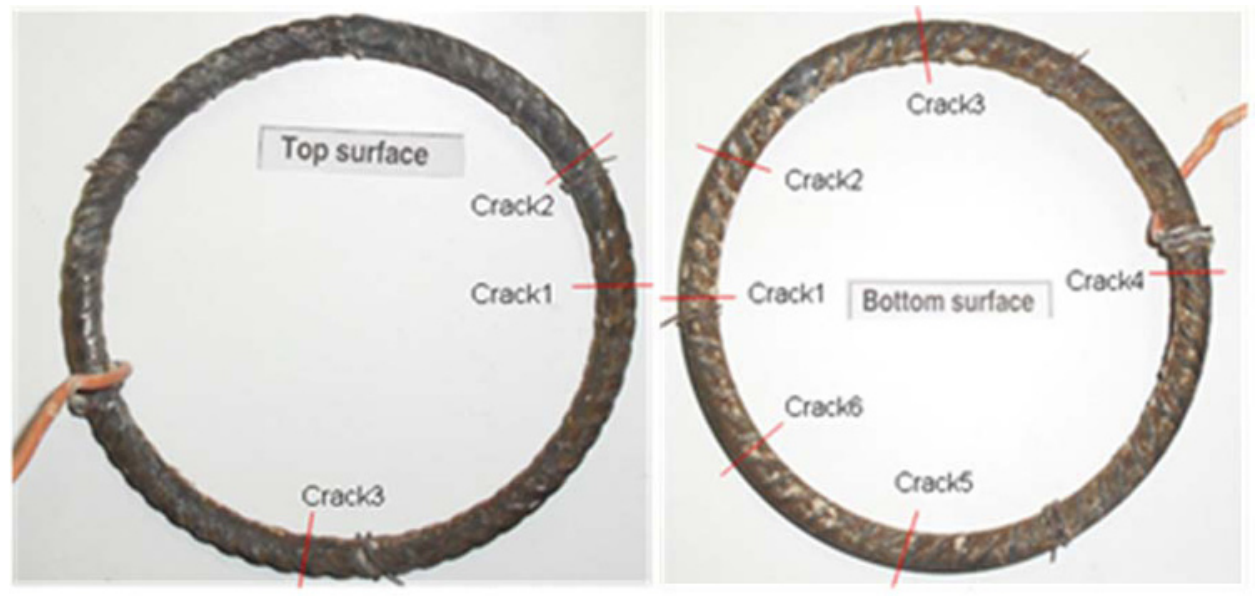

Fig. 5. Locating of mechanical cracks and real corrosion on steel bar of C2 sample.

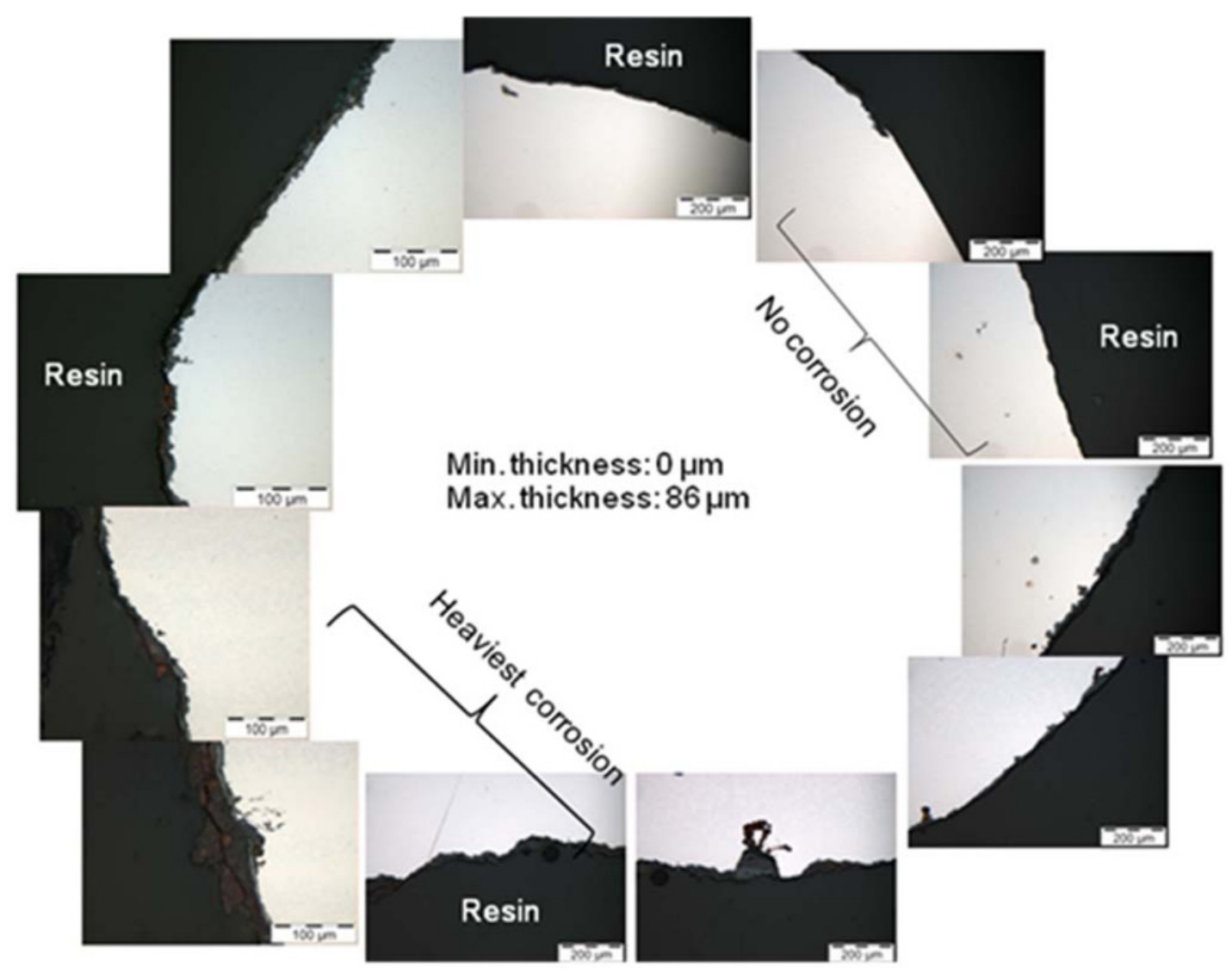

Fig. 6. Variation of rust layer thickness around a cross section of steel bar at location of crack3 (top face) for C2 sample. 


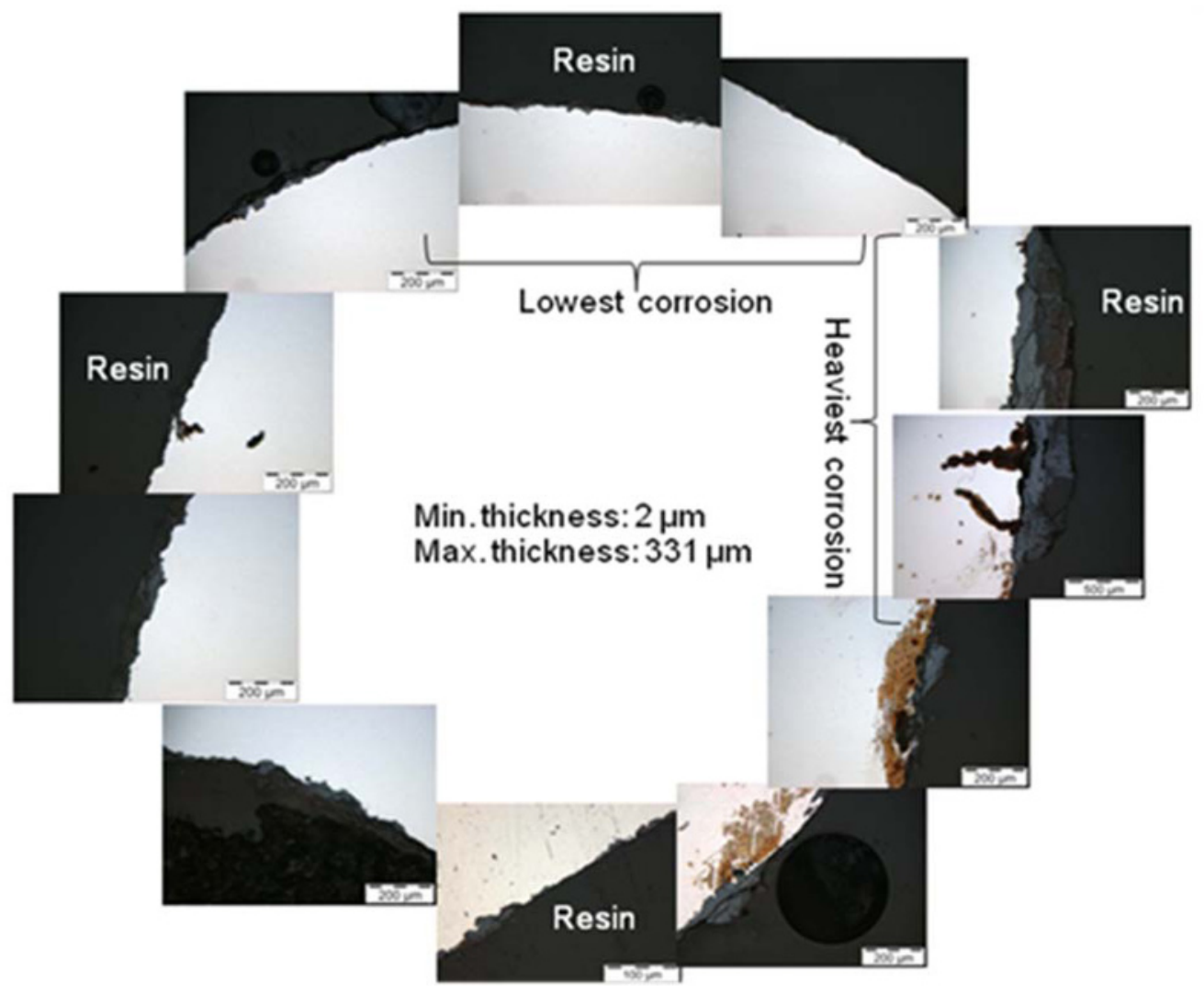

Fig. 7. Typical cross section of rust layer formed on S6 sample.

\section{Conclusion}

A preliminary study on corrosion state of reinforcement steel embedded mortar samples in carbon dioxide conditions and then cycles of wetting- drying was carried out. The experimental results showed that in case of mechanically cracked specimens, whatever crack widths allow carbon dioxide to reach the steel-mortar interface. The corrosion starts and then spreading this interface. This also observed by S. Alahmad et al. [2].

The samples then subjected to wetting-drying cycles exhibited corrosion development all along the interface. Nevertheless, the corrosion is not uniform along the perimeter of a given cross-section, which could be link to the casting direction effect. The corrosion rate is generally higher on the bottom of the section than that on the top of the section.

\section{References}

[1]. CEB., 1997, "Durable of concrete structures", Thomas Telford.

[2]. S. Alahmad, A. Toumi, J. Verdier, R. François, 2009, "Effect of crack opening on carbon dioxide penetration in cracked mortar samples”, Materials and Structures (2009) 42:559-566. 
[3]. Peter Schießl and Michael Raupach, 1997, "Laboratory Studies and Calculations on the Influence of Crack Width on Chloride-Induced Corrosion of Steel in Concrete”, ACI Materials Journal, V. 94, No. 1, January-February 1997.

[4]. Tarek Uddin Mohammed, Nobuaki Otsuki, Makoto Hisada, and Tsunenori Shibata, 2001, "Effect of crack width and bar types on corrosion of steel in concrete", Journal of materials in civil engineering / May/June 2001.

[5]. A.W.Beeby, 1983, "Cracking, cover, and corrosion of reinforcement”, Concrete international/ February 1983, pp.35-40.

[6]. Raoul François, Ginette Arliguie, 1998, "Influence of service cracking on reinforcement steel corrosion", Journal of materials in civil engineering / February 1998.

[7]. M.B. Otieno, M.G. Alexander \& H.D. Beushausen, 2009, "Corrosion propagation in cracked and uncracked concrete", 2nd International Conference on Concrete Repair, Rehabilitation and Retrofitting, ICCRRR-2, 24-26 November 2008, Cape Town, South Africa, pp. 339-344.

[8]. Gagné.R, François.R, Masse.P, 2001, "Chloride penetration testing of cracked mortar samples”. In: Banthia N, Sakai K, Gjory OE (2001) Concrete under severe conditions, vol 1. University of British Columbia, Vancouver, pp 198-205.

[9]. C.Andrade and C.Alonso, 2004,"'Test methods for on-site corrosion rate measurement of steel reinforcement in concrete by means of the polarization resistance mothod", RILEM TC 154-EMC: Electrochemical techniques for measuring metallic corrosion. Materials and structures, Vol. 37, November 2004, pp 623-643.

[10]. Raoul Francois, Inamullah Khan, Ngoc Anh Vu, Hugo Mercado and Arnaud Castel, 2012,"Study of the impact of localized cracks on the corrosion mechanism", European journal of environment and civil engineering, DOI:10.1080/19648189.2012.667982.

[11]. R.Francois and J.C.Maso, 1988, "Effect of damage in reinforced concrete on carbonation or chloride penetration”, Cement and Concrete Research, Vol.18 (1988), pp. 961-970.

[12]. In-Seok Yoon, Oguzhan Copuroglu, Ki-Bong Park, 2007, "Effect of global climatic change on carbonation progress of concrete”, Atmospheric Environment 41 (2007) 7274-7285.

[13]. L.J.Parrott, 1994, “A Study of Carbonation-Induced Corrosion”, Magazine of Concrete Research, 1994, 46 (3): 23-28. 